\title{
APPLIANCE
}

\section{A NEW SUTURE NEEDLE FOR CORNEAL SURGERY*}

\author{
BY \\ C. A. PITTAR \\ Auckland, New Zealand
}

It occurred to me some time ago that, if one used a straight needle so that in placing sutures there was no bending force applied by the needle-holder, this needle could be greatly reduced in diameter. This smaller cross-section would in turn allow it to penetrate tough tissue such as the cornea much more easily.

Further, I felt that with a straight needle one could place sutures much more accurately in that one could gauge the point of exit more exactly. For instance, in direct suturing of corneal grafts, one wants to introduce the needle near the edge of the epithelial surface and to bring it out on the cut edge of the graft. It must not go through to the endothelial surface nor must it take too shallow a bite. With the normal curved needle this can be quite difficult to gauge, but with a straight needle the angle is easy to judge in order to bring it out at the correct depth. There is also no risk of this needle cutting out as there is with a curved needle going shallow.

I therefore had a straight needle made from 15-gauge wire material which has a diameter of only 0.010 inches. It was $4 \mathrm{~mm}$. long, triangular pointed, and flattened at the other end for the eye. For comparison it may be noted that the ordinary No. 6 curved eye needle is made from 10-gauge and the standard Jameson Evans corneal needle from 12-gauge wire (Evans, 1954).

I have given these needles an extended trial for 8 or 9 months, using them particularly for suturing penetrating corneal grafts and for edge-to-edge suturing of cataract sections. I have also used Jameson Evans and Grieshaber needles during this period for comparison. In some corneal grafts with multiple sutures, I have put in some sutures with the straight and some with the curved needles in the same case.

I have found the straight needles very satisfactory for the following reasons:

(1) They penetrate the cornea more easily and cause much less trauma.

(2) There is less tendency for the sutures introduced by them to cut out than for those introduced by curved needles. This has been proved in corneal grafts in which both types of needle have been used and sutures left in for up to 28 days.

(3) They can be placed more accurately, and being so short they can be pulled through without difficulty and with no danger of injuring underlying structures 
such as the lens. In placing them in the recipient cornea of an eye being grafted, the cornea can be raised sufficiently to make their insertion quite safe.

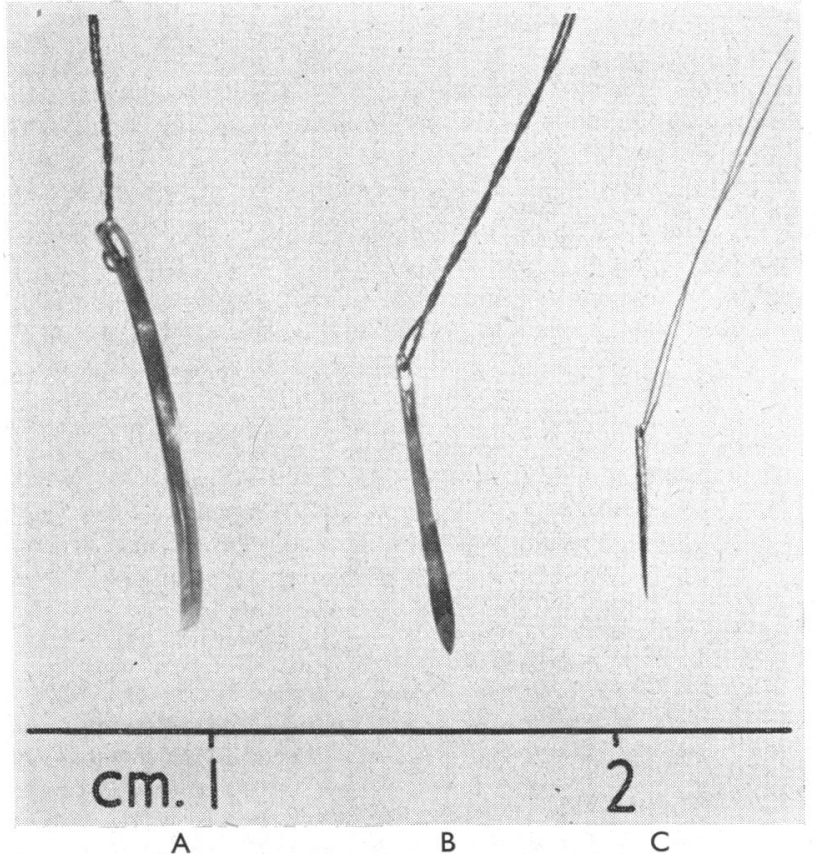

A. No. 6 eye curved needle. B. Jameson Evans needle. C. Straight needle.

(The thread on the two curved needles is $6 / 0$ silk.) $\times 4$.

The disadvantages of these needles as compared with the more conventional curved needles are small, and may be summed up as follows:

(1) Because of their very small size threading them may be difficult without a binocular loupe. For all practical purposes the largest thread that will go through the needle is $6 / 0$ silk or catgut. For corneal grafting I have been using some monofilament material so fine that it is not only easy to thread but falls out if not tied on to the needle. It is however so fine that the knot offers no obstruction at all.

(2) The needle may sometimes tend to turn sideways in the needle-holder if during the insertion the pressure is not kept directly in its long axis. This is largely overcome by using a very accurate needle-holder and gripping the needle close to the flattened end. I use a Barraquer needle-holder with no serrations on the jaws which I find very satisfactory.

(3) So far these needles have only been made from carbon steel, as stainless steel was not available in this gauge at the time. If this can be obtained in the future it should be used in preference to avoid rusting.

I am greatly indebted to the principals of Shrimpton and Fletcher Ltd., Redditch, England, for their help and advice in designing and making these needles.

REFERENCE

Evans, P. JAMESON (1954). British Journal of Ophthalmology, 38, 630. 